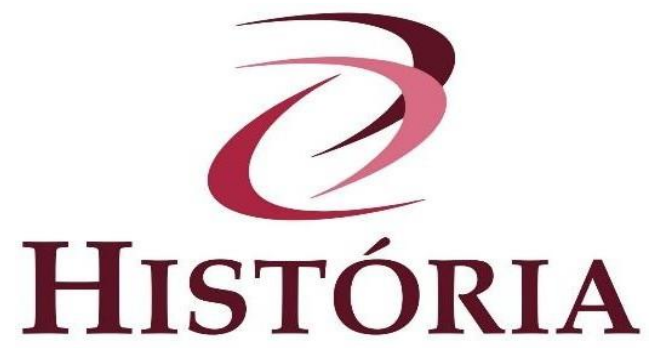

\title{
Estigmas à imagem pública: registros da violência de gênero nos papéis da Inquisição portuguesa
}

\section{Stigmas to the public image: records of gender violence in the Portuguese Inquisitorial papers}

\section{Estigmas a la imagen pública: registros de violencia de género en los manuscritos de la Inquisición portuguesa}

Um dos mais clássicos temas da historiografia que se debruça sobre a história da Inquisição portuguesa é, sem dúvidas, a violenta perseguição que a instituição promoveu às muitas vítimas ao longo de seus quase três séculos de existência (1536-1821). Em meio a uma vasta gama de temáticas possíveis, como a perseguição religiosa, a moralização do comportamento e o exercício de regulação das hierarquias sociais, tem certo destaque os estudos sobre as mulheres vitimadas de diferentes maneiras pela ação do Santo Ofício. Tendo como objeto de estudo desde as que foram perseguidas por realizarem práticas mágico-religiosas, reputadas por isso como bruxas e feiticeiras, passando pelas matriarcas que perpetuavam secretamente a tradição judaica em famílias cristãs-novas, os estudos de gênero na Inquisição portuguesa têm se renovado e ampliado seu escopo de interesse nas últimas décadas (SOUZA, 1986; MOTT, 1993; GOREINSTEIN, 2005; ASSIS, 2012; ROCHA, 2016; REIS, 2019).

O manuscrito apresentado a seguir é um registro bastante relevador das hostilidades às quais as mulheres estavam submetidas no Portugal da Época Moderna, e presta-se como interessante fonte de pesquisa sobre questões de gênero no Antigo Regime português. Trata-se de um processo de habilitação oriundo da subsérie documental Habilitações Incompletas, pertencente ao fundo documental do Tribunal do Santo Ofício, sob guarda patrimonial do Arquivo Nacional da Torre do Tombo, em Lisboa. Neste imenso fundo estão acautelados a imensa maioria dos papeis produzidos pela Inquisição portuguesa ao longo de seu 
funcionamento, e as Habilitações Incompletas, como seu nome explicita, é a subsérie que aloca processos de habilitação para cargos do Tribunal do Santo Ofício que ficaram inconclusos. Ela é composta por 5428 registros processuais em papel e pergaminho, dispostos em ordem alfabética, alocados em 133 caixas e produzidos entre os anos de 1588 e 1820. Nela estão acondicionados processos de habilitação de candidatos residentes em toda a extensão do Império português, entre os séculos XVI e XIX, que, por diferentes razões, não tiveram continuidade ou parecer favorável à obtenção de cargos inquisitoriais peticionados. ${ }^{i}$

Em meio às Habilitações Incompletas é possível encontrar 150 processos referenciados em cotas arquivísticas por nomes femininos, apesar da existência neste fundo documental de uma subsérie a parte, intitulada Habilitação de Mulheres. ${ }^{\text {ii }}$ Trata-se de processos de habilitação de cônjuges de familiares do Santo Ofício habilitados, uma vez que, para se casarem, estes funcionários laicos do tribunal precisavam demonstrar que suas noivas e esposas também se enquadravam nas exigências regimentais da instituição, como ter limpeza de sangue, boa reputação da honra e antepassados nunca penitenciados pela Inquisição. Há, ainda, diversos outros casos de processos de habilitação de mulheres com o mesmo enredo, mas inscritos em cotas documentais de nomes masculinos, isto é, sob nomes dos próprios agentes inquisitoriais com quem se casariam. Este é o caso preciso do documento transcrito adiante.

O documento 1779 das Habilitações Incompletas, inscrito sob a cota nominal de Francisco José Martini, guarda um curto processo de habilitação, restrito apenas às páginas da petição e dos pareceres dos inquisidores de Coimbra e do Conselho Geral do Santo Ofício. ${ }^{\text {iii }} \mathrm{O}$ enredo nele registrado é o de um familiar daquela Inquisição solicitando no ano de 1762 a licença do tribunal para contrair núpcias com Ana Felícia Magro, uma moça natural daquela mesma cidade a quem o agente prometera casamento. $\mathrm{O}$ interesse por este manuscrito está na reveladora solicitação feita pelo agente inquisitorial: seria necessária uma dispensa do Inquisidor Geral que autorizasse a noiva a contrair núpcias com um agente pelo fato de ela ter um antepassado penitenciado pela Inquisição.

Segundo relatara o familiar em sua petição, dona Ana Felícia Magro era neta pelo tronco materno de Manuel Cabral, homem que havia sido alcaide da Inquisição de Coimbra nas primeiras décadas do século XVIII. No desempenho de suas funções, Cabral cometera "tocamentos lascivos com algumas presas, jactando-se disso na presença dos guardas", ou seja, contara vantagens publicamente dos abusos sexuais que cometia contra mulheres detidas nos cárceres do Santo Ofício. Por este motivo, Manuel Cabral foi preso no ano de 1718 pela própria Inquisição à qual servia, ficou detido por dois anos, foi processado e condenado. ${ }^{\text {iv }}$ 
A função de um alcaide da Inquisição - tanto o dos cárceres secretos ou da penitência - era a de receber os presos encaminhados à detenção e vigiar seus atos a fim de denunciar qualquer prática considerada herética (LIPINER, 1999, p. 26). Portanto, além de carcereiro, seu papel regimental era sondar o comportamento dos presos, e tal função permitia a este agente do Santo Ofício certo poder sobre a condição dos detidos pelo tribunal. Como chama atenção Isabel Drumond Braga, muitas situações insólitas ocorriam no cotidiano dos cárceres inquisitoriais portugueses. Em seu livro Viver e morrer nos cárceres do Santo Ofício, Drumond Braga recupera o cotidiano inóspito das prisões inquisitoriais e retrata casos de mulheres violentadas e que até mesmo pariram nos cárceres. Ainda segundo a autora, carcereiros diversas vezes praticavam toda sorte de comportamentos contra os réus detidos, e o assédio às mulheres presas foi circunstância corrente. A Inquisição até buscava reprimir e punir institucionalmente os agentes pegos em comportamentos desta natureza, como no caso relatado neste documento, mas também soube se valer destes para levantar informações do que se passava no dia a dia daquelas insalubres prisões.

O manuscrito apresentado a seguir registra ainda outro tipo de violência patriarcal daquela sociedade: a honra feminina publicamente colocada em xeque em razão do comportamento sexual não endossado pela Igreja católica. Francisco José Martini, o agente do Santo Ofício que escrevera ao Conselho Geral, solicitava a dispensa dos embaraços familiares de sua noiva para com ela se casar no intuito de mitigar o prejuízo de sua reputação, em razão de tê-la desonestado. Segundo ele mesmo, a fama pública corroía a honra da moça, pois por "ser notório nas vizinhanças das moradas da [?] e a sobred dever a esta aquelle a honra", precisavam se casar rapidamente, admitindo ele que a "fama só ceçará recebendo o $S^{\text {to }}$ Matrimonio". Assim, por ter se comprometido "por palavras de futuro" com dona Ana Felícia Magro, o familiar do Santo Ofício requeria ao Inquisidor Geral a dispensa do óbice que impedia a habilitação de sua noiva pela instituição. Ao cabo, argumenta o agente inquisitorial que o gravíssimo prejuízo da honra da moça poderia ser reparado pelo Santo Ofício, pois entendia que "a Mizericordia deste Il ${ }^{\text {mo }}$ Tribunal, e q assimesmo pode condenar pode restringir". Como se vê, Martini por estas palavras reconhecia e valorizava a capacidade de regulação social da honra que a Inquisição possuía em suas decisões e esperava por meio da autorização da instituição emendar a reputação da mulher que desflorou.

Pelos documentos até aqui conhecidos não se sabe se o Tribunal concedeu ou não a dispensa necessária para dona Ana se casar com o agente laico do Santo Ofício. Apesar de o Conselho Geral deliberar pela realização de investigações em parecer de 18 de maio de 1762 , a falta de novos trâmites do processo indica que as mesmas não foram realizadas. Também não 
há no processo qualquer despacho do Inquisidor Geral deliberando pela concessão ou não da dispensa requerida. No entanto, a despeito do desdobramento da trama, nos interessa aqui destacar o préstimo que documentos como este têm para o estudo das estruturas patriarcais normativas daquela sociedade. Esta transcrição de fonte comentada vem chamar atenção para o potencial informativo que têm as mais variadas tipologias documentais do Tribunal do Santo Ofício português para os estudos acerca da história das mulheres, para a compreensão do processo generativo da misoginia enquanto comportamento social estruturante, e para a dimensão patriarcal que forjou o funcionamento da Inquisição portuguesa ao longo de sua história.

Na transcrição do manuscrito optou-se por manter as abreviaturas e os termos como no documento original, sem qualquer atualização ortográfica.

$$
* * *
$$

[Folha 1]

Os Inquiz ${ }^{\text {res }}$ de Coimbra informem com seu parecer. Lisboa, 23 de abril de 1762.

[Sinal público] [Sinal público]

II $^{\text {mo }}$ Senhor

Diz Francisco José Martini, Cavaleiro profeço na Ordem de Christo e Familiar do $\mathrm{S}^{\text {to }} \mathrm{Of}^{\mathrm{fo}}$ da Inquiz $^{\text {am }}$ de Coimbra, q ele se acha contratado e compermetido $\mathrm{p}^{\mathrm{a}}$ casar por palavras de futuro com Ana Filicia Magro da mesma cide e por q. pôr em pratica o s. ${ }^{\text {to }}$ Matrimonio carece de licença de V. Il. ${ }^{\text {ma }}$

$\mathrm{P}^{\mathrm{a}} \mathrm{V} . \mathrm{Il}^{\mathrm{ma}}$ se digne precedendo as delig. ${ }^{\text {as }}$ ordinarias, concederlhe a licença q. pede.

E. R M.

Declara o supp. ${ }^{\text {e }}$ ser a sobred ${ }^{\mathrm{a}}$ f. ${ }^{\mathrm{a}}$ leg. ${ }^{\mathrm{a}}$ de Manoel Francisco da Costa, e sua mulher Antonia Cabral de $\mathrm{S}^{\text {ta }}$ Roza mores ${ }^{\mathrm{es}} \mathrm{d}^{\mathrm{a}}$ cid $^{\mathrm{e}}$

Neta pela $\mathrm{p}^{\mathrm{e}}$ Paterna de Miguel Gon ${ }^{\text {ces }}$ Affonço e sua $\mathrm{m}^{\mathrm{er}} \mathrm{M}^{\mathrm{a}}$ Francisca, naturaes de Pedra Vedra, freg $^{\mathrm{a}}$ de S; Christova, da V. ${ }^{\mathrm{a}}$ de Mondim de Basto, Comarca de Villa Real, Arcebispado de Braga, donde também hé n. ${ }^{\text {al }}$ o d..$^{o}$ seu pay.

E netta Materna de Manoel Cabral Familiar qfoi do S. ${ }^{\text {to }}$ Off. ${ }^{\circ}$ e de sua mulher Felipa Marques, naturaes ambos da d. ${ }^{a} \mathrm{Cid}^{\mathrm{e}}$. de Coimbra, e freg. ${ }^{\mathrm{a}} \mathrm{de} \mathrm{S}$. Thiago.

O avô materno da Supp. ${ }^{\mathrm{e}}$ foi penitenciado pelo sempre retíssimo Tribunal do S. ${ }^{\text {to }}$ Off. de Coimbra por erros q cometeu no Officio de Alcaide dos Carceres Se- 


\section{[Folha 1v.]}

Secretos E como o supp ${ }^{e}$ se vê indispensavelm ${ }^{\text {te }}$ percizado a receber por sua $m^{\text {er }}$ a sobred ${ }^{a}$, nam só por assim lhe ter prometido, mas ser notório nas vizinhanças das moradas da [?] e a sobred ${ }^{a}$ dever a esta aquelle a honra, cuja fama só ceçará recebendo o $S{ }^{\text {to }}$ Matrimonio $p^{a}$ dissolução do qual não basta a infamia da sobred ${ }^{a}$; por nam ser das de Direito declara impeditivas por respeitar só a pureza com q este retíssimo Tribunal destingue seus oficiaes: e por o supp deseja a salvaçam de sua alma recorre à clemência de Il ${ }^{\text {ma }}$ para que se digne a dispensar aquella infamia $p^{a} q$ o supp..$^{e}$ receba a sobred ${ }^{a}$ em atençam a nam ser ella a q hade servir o . $^{\text {to }}$ Off. ${ }^{o}$, mas sim a suppção gravíssimo e irreparável prejuízo q se segue á sobred ${ }^{a}$ no seu cred., honra e fazenda; pois hé indubitavel a Mizericordia deste $I^{\text {mo }}$ Tribunal, e q assimesmo pode condenar pode restringir.

[Folha 2 em branco]

[Folha 2v. em branco]

[Folha 3]

Os Inquiz ${ }^{\text {res }}$ de Coimbra mandem fazer dilig. A futtura mulher do Supp ${ }^{\text {te }}$ e feitas na forma do Regimento se enviem ao Conselho. Lisboa 18 de mayo de 1762.

[Sinal Público] [Sinal Público]

Francisco José Martini, Familiar do $S^{\text {to }}$ Ofício, conteúdo na petição incluza, que V. Ix ${ }^{a}$ nos manda informar, pede a V. Ixa licença para casar com Anna Felicia Magro, dizendo que se acha precisado a faze-lo em desgargo de sua consciência, tanto por lhe ter prometido, como por ser notório na sua vizinhança que ele lhe deve a honra. Juntam te pede a $V$. I $x^{a}$ lhe dispense no impedime ${ }^{\text {to }}$ de ter sido penitenciado no to $^{\text {to }}$ Off. ${ }^{o}$ o Avo materno da sobredita.

No correio de 15 de julho de 1756 chegou a esta Meza uma petição de Leandro Anastácio de Carvalho e Fonseca com despacho para familiar, o qual hé cazado com uma irmãa inteira da $d^{a}$ Anna Felícia Magro; e ainda que por descuido não ficou registro do correio em que voltou para o Conselho, há lembrança que a Meza informou dando o seu parecer a favor da habilitaçam; mas athé o prezente não tornou para diligencias.

Hé certo q Manuel Cabral, Avo materno das sobreditas foi Alcaide dos Carceres desta Inquisiçam; e por erros

\section{[Folha 3v.]}

de seu ofício, que consistirão em tocamentos lascivos com algumas prezas, jactando-se disso na prezença dos Guardas, e perguntar às mesmas que matérias se praticavam com ellas na Meza, foi preso em hum cárcere e processado, sendo ultimam ${ }^{\text {te }}$ julgado por assento do Conselho Geral de 26 de abril de 1720. Com a pena de privação do ofício de Alcayde, inabilitado para mais servir ao .to $^{\text {to }}$ Off. ${ }^{\circ}$ e degredado por déz anos para Angola: ouviu esta 
sentença no Auto publico da Fé que se celebrou no Terreiro de S. Miguel desta cidade em 7 de julho do do anno.

Nam consta que seja notória a fama da comunicação torpe que este Familiar alega entre ele e a sobredita Anna Felicia; nem há meio de averiguar a promessa de cazamento, que diz lhe tem feito; porem sendo $V . I x^{a}$ servindo dispensala no dito impedimento, parece-nos que não tem outro por onde desmereça a merce pretendida.

V. $E x^{a}$

[Folha 4.]

mandará o que for mais justo. Coimbra em Meza de 10 de mayo de 1762.

[Sinal Público] [Sinal Público] [Sinal Público]

[Folha 4v. em branco]

\section{Referências bibliográficas:}

ASSIS, Angelo A. F. de. Macabeias da Colônia: criptojudaismo feminino na Bahia. São Paulo: Ed. Alameda, 2012.

BRAGA, Isabel D. Viver e morrer nos Cárceres do Santo Ofício. Lisboa: Esfera dos Livros, 2015.

GORENSTEIN, Lina. A Inquisição contra as mulheres. Rio de Janeiro, Séculos XVI e XVIII. Rio de Janeiro: Editora Humanitas, 2005.

LIPINER, Elias. Terror e linguagem: um dicionário da Santa Inquisição. Lisboa: Editora Contexto, 1999.

LOPES, Luiz Fernando Rodrigues. Indignos de servir: os candidatos rejeitados pelo Santo Ofício português (1680-1780). Tese de doutorado. Mariana: ICHS-UFOP, 2018.

MOTT, Luiz. Rosa Egipcíaca: uma santa africana no Brasil. Rio de Janeiro: Bertrand Brasil, 1993.

REIS, Marcus Vinicius. Descendentes de Eva: práticas mágico-religiosas e relações de gênero a partir da Primeira Visitação do Santo Ofício à América portuguesa (1591-1595). Curitiba: Editora CRV, 2018.

ROCHA, Cássio B. de A. Masculinidades e Inquisição: gênero e sexualidade na América portuguesa. Jundiaí: Paco Editorial, 2016. 
SOUZA, Laura de Mello e. O diabo e a Terra de Santa Cruz: feitiçaria e religiosidade popular no Brasil colonial. São Paulo: Companhia das Letras, 1986.

Recebido em: 20/02/2021

Aprovado em: 20/03/2021

Publicado em: 07/05 2021

\section{Notas}

* Doutor em História. Docente do Instituto Federal de Brasília - IFB luizfernando_rl@yahoo.com.br https://orcid.org/0000-0003-4391-9300 ; http://lattes.cnpq.br/3855363077503120.

${ }^{\mathrm{i}}$ Em minha tese de doutoramento realizei um levantamento sistemático de todos os 5428 processos depositados nesta subsérie, identificando o período de tramitação e o local de origem destes documentos no espaço do Império português.

ii Arquivo Nacional da Torre do Tombo (ANTT), Tribunal do Santo Ofício (TSO), Conselho Geral (CG), Habilitações de Mulheres. Esta subsérie apresenta 86 processos de mulheres casadas ou preste a se casarem com ministros inquisitoriais, quase sempre familiares do Santo Ofício. Há ainda uma pequena parcela de habilitações para servirem como amas do Paço. Para consulta on-line dos catálogos da subsérie no site Digitarq, ver o seguinte código de referência: PT/TT/TSO-CG/A/008-003.

iii ANTT, TSO, Habilitações Incompletas, documento 1779 . Disponível em: http://digitarq.arquivos.pt/viewer?id=2345804. Acesso em 01/03/2021.

iv ANTT, TSO, Inquisição de Coimbra, processo 7833. Manuel Cabral. 